(i) Laura Lucía Bogado Bordazar

Recibido

Aceptado:

Resumen

Palabras clave

Abstract

Universidad Nacional de La Plata, Argentina

lbogadobordazar@gmail.com

\title{
Un recorrido por los 30 años de vigencia del Tratado de Asunción y su reflejo en la construcción del proceso de integración regional del Mercosur
}

\author{
A tour through the 30 years of effectiveness of the Treaty of Asun- \\ ción and its impact on Mercosur's regional integration process
}

\section{$17 / 9 / 2021$}

\section{$23 / 12 / 2021$}

En el presente artículo realizaremos un recorrido por las principales dimensiones que surgen del Tratado de Asunción y que se han ido desplegando en sus treinta años de existencia. Nos aventuramos a afirmar que el Tratado no ha sido un simple acuerdo entre partes del cual surgieron derechos y obligaciones, sino que ha sido el fundamento jurídico y el impulso teórico de los postulados regionalistas y unionistas, cuyos objetivos trascendieron los límites de los intereses económicos y comerciales para encuadrarse -al menos en lo teórico- en un modelo de integración multidimensional que abarca lo económico, político, social y cultural. El Tratado de Asunción se presenta, en este sentido, como el germen fundacional del Mercosur.

\section{Mercosur, integración, Tratado de Asunción, modelo social, dimensiones}

In this article we will take a tour of the main dimensions arising from the Treaty of Asunción, which have been unfolding in its thirty years of existence. We note that the Treaty has not been a simple agreement between parties triggering rights and obligations, but rather that it has been the legal basis for and the theoretical drive of the regionalist and unionist postulates whose objectives went beyond the limits of economic and commercial interests to fit - at least theoretically - into a multidimensional integration model encompassing economic, political, social and cultural aspects. As such, the Treaty of Asunción is presented as the founding seed for Mercosur.

Keywords: Mercosur, integration, Treaty of Asunción, social model, dimensions

Cómo citar este artículo: Bogado Bordazar, L. L. (2021). Un recorrido por los 30 años de vigencia del Tratado de Asunción y su reflejo en la construcción del proceso de integración regional del Mercosur. Revista Electrónica de Derecho Internacional Contemporáneo, 4(4), 026. https://doi.org/10.24215/2618303Xe026 


\section{Introducción}

En marzo de 2021 se celebraron los 30 años de la firma del Tratado de Asunción lo que significó un hito importante para nuestro proceso de integración. Muchas son las reflexiones que podemos realizar sobre este período si prestamos atención a los debates que se han planteado sobre los alcances de la norma, el impacto de la gesta integracionista en la región y los beneficios/perjuicios de pertenecer al bloque, entre otros. El recorrido histórico ha sido muy dinámico, porque la vida de los tratados así lo es. En el presente artículo haremos un recorrido por esa historia plagada de proyectos, trayectorias y discusiones que reflejan de alguna manera las principales características de nuestras sociedades que se han cristalizado en un tratado, considerado el punta pie inicial de un proceso de integración que lleva tres décadas de existencia muy dinámica.

El primer éxito entonces estuvo marcado por la concreción de una idea, de una política y de un proyecto que durante décadas fue pensado y diseñado estratégicamente por dirigentes políticos, sindicalistas, representantes de diversos sectores de la sociedad civil, diplomáticos, funcionarios, pensadores y académicos ${ }^{1}$ que apostaron a la integración y a concretar agendas pendientes entre los países del Cono Sur de América del Sur. Agenda de integración que, como sabemos, tuvo sus antecedentes remotos en el Pacto de No Agresión, Consulta y Arbitraje ratificado en 1915 entre Argentina, Brasil y Chile (Pacto ABC), el cual se había planteado entre sus objetivos, generar una política de equilibrio de poder regional entre los socios (Pávez, 2017) y que tuvo su intento de reedición en la década del 50 con los mismos protagonistas e igualmente escaso de éxito. Con posterioridad los antecedentes los encontramos en los tratados de la década de $1960^{2}$ primero y de $1980^{3}$ después, fundamentados ambos en las alianzas integracionistas y desarrollistas propuestas por la Comisión Económica para América Latina y El Caribe (CEPAL) de las Naciones Unidas, que se plasmaron en fuentes escritas del derecho internacional público contemporáneo.

No obstante, los proyectos conjuntos entre los países de la sub región, han tenido otros abordajes. No podemos dejar de mencionar en este sentido, la celebración en 1969 del Tratado de la Cuenca del Río de La Plata, que reúne a los siguientes países: Argentina, Brasil, Bolivia, Paraguay y Uruguay y que ha impulsado desde sus orígenes la gestión conjunta y cooperativa de dicho recurso hídrico, lo cual significa -en términos estratégicos- un punto sustancial para la consolidación de la integración regional en el Cono Sur en lo referente al uso compartido de la Cuenca internacional ${ }^{4}$ (Caetano Hargain, 2009).

Asimismo, y a partir de la creación de la Asociación Latinoamericana de Integración -ALADI- (1980) los países de la sub región celebraron sendos acuerdos bilaterales que implicaron un avance importante hacia la concreción del Mercosur. A modo de ejemplo citamos el Acuerdo de Alcance Parcial No. 1 celebrado entre Argentina y Uruguay (1982) que implicó la adecuación del Convenio de Cooperación Económica que había sido suscrito entre ambos actores en 1974. Este acuerdo tenía por objetivos -entre otros-intensificar y diversificar al grado máximo posible el comercio recíproco entre ambos países, coordinar actividades industriales,

\footnotetext{
${ }^{1}$ Para profundizar en los antecedentes filosóficos remotos de la integración regional sudamericana ver: Simonoff, A. (2014). Pensadores del Cono Sur. Los aportes de Jaguaribe, Methol Ferré, Puig y Tomassini a las Relaciones Internacionales. Documento de Trabajo No. 8 Instituto de Relaciones Internacionales (IRI-UNLP). https://www.iri.edu.ar/images/Documentos/documentos/doc_trab_8.pdf

2 El Tratado de Montevideo de 1960 dio origen a la Asociación Latinoamericana de Libre Comercio (ALALC).

${ }^{3}$ El Tratado de Montevideo de 1980 fue el creador de la Asociación Latinoamericana de Integración (ALADI).

${ }^{4}$ Cabe mencionar que la Cuenca del Río de La Plata es la cuenca hidrográfica más rica en agua dulce del mundo y una de las zonas más fértiles. Abarca distintos porcentajes de la superficie de cinco países, existen 57 ciudades con más de 100.000 habitantes, incluyendo cuatro de las capitales de los cinco países que la componen (sólo La Paz queda fuera de su órbita). Posee una extensa red navegable y un muy importante potencial hidroeléctrico. La extensión geográfica que abarca la cuenca equivale a un sexto del territorio latinoamericano o a un tercio de Europa (Caetano Hargain, 2009).
} 
estimular las inversiones dirigidas al aprovechamiento de los mercados y facilitar la creación y funcionamiento de empresas binacionales (artículo 1). En este sentido, los países acordaron un programa de liberación de gravámenes arancelarios y demás restricciones a la circulación y un régimen de origen, así como también un esquema de coordinación de políticas comerciales, de planificación y acciones conjuntas en materia de infraestructura para solucionar problemas que incidan negativamente en el proceso de integración (artículo 21). O el Acuerdo de Alcance parcial $N^{o} 7$ (1986) celebrado entre Argentina y Brasil y luego reemplazado por el Acurdo No. 14 de 1990 (ACE 14).

Con mayor o menor intensidad las décadas previas a la firma del Tratado de Asunción estuvieron impregnadas de una riqueza de pensamiento regionalista bastante diverso, tendiente a armar un esquema progresivo de integración, lo cual fue generando distintos procesos y acuerdos a lo largo y a lo ancho de América Latina.

Para realizar el recorrido de los treinta años de vigencia del Tratado de Asunción proponemos la siguiente metodología: (i) en primer lugar, analizar los antecedentes inmediatos del Tratado con el objetivo de identificar las características que tuvo la transición integracionista y las "huellas" que fueron dejando hasta la firma del mismo. (ii) En segundo lugar, a partir de 1991 nos detendremos en las distintas dimensiones de la integración que se desplegaron a partir de la firma del Tratado de Asunción. Este análisis tendrá en cuenta, por un lado, los ejes centrales plasmados en el mencionado acuerdo así como también los que surgieron en forma indirecta con posterioridad y, por otro, la influencia del devenir social político y económico de los distintos países que componen el bloque y de los vaivenes de la política internacional. (iii) Por último, haremos algunas reflexiones sobre la historia del Tratado y en definitiva del objetivo principal del tratado que fue el de generar un proceso de integración regional.

\section{El intenso recorrido hasta la firma del Tratado de Asunción}

La Declaración de Foz de Iguazú -también denominada Acta de Foz de Iguazú- firmada el 30 de noviembre de 1985 en la ciudad brasileña del mismo nombre, por el presidente argentino Raúl Alfonsín y su par brasileño José Sarney, fue el acuerdo político más importante realizado entre los dos países y se lo reconoce como el antecedente inmediato del Mercosur. En esta Declaración se acuerda la creación de una Comisión Mixta de Alto Nivel para la Integración que definiría las bases para la formulación del futuro espacio de complementación regional y el diseño de la modalidad de desarrollo del proceso.

Para entender el trabajo que se le había encargado a esa Comisión es necesario recordar el contexto latinoamericano, marcado por una deuda externa muy elevada, dependencia de mercados externos, falta de créditos para la producción, pobreza, altos niveles de desempleo y la consecuente desigualdad en la distribución de la riqueza. Tanto Argentina como Brasil habían iniciado un proceso de construcción democrática dejando atrás violentas dictaduras que generaron todos los males mencionados. Ambos países se enfrentaban a situaciones de crisis económicas y sociales que los impulsaba necesariamente a reorientar sus economías y también sus modelos de desarrollo, con lo cual podemos afirmar que el acercamiento bilateral propició la construcción de una integración política profunda, que trascendió a la idea comercial y modificó la tradicional visión de competencia y conflicto entre Brasil y Argentina, dando paso a la cooperación (Acta de Foz de Iguazú, 1985).

En el marco del programa establecido en el Acta de Foz de Iguazú, se aprobaron diversos convenios que suscribieron al modelo amplio de integración incorporando a la agenda bilateral temáticas como: estímulo a la complementación de los sectores empresariales, modernización tecnológica y una armonización progresiva de políticas económicas (Acta de Buenos Aires, 1986). Con este enfoque en 1988 se firmó el Tratado de Integración, Cooperación y Desarrollo, que tenía por objetivo la eliminación de todos los obstáculos tarifarios

\footnotetext{
${ }^{5}$ Este acuerdo planteaba objetivos estratégicos a largo plazo: facilitar las condiciones necesarias para el establecimiento del mercado común entre ambos países; promover la complementación económica, en especial la industrial y tecnológica, con el fin de optimizar la movilidad de los factores de la producción y estimular las inversiones para el óptimo aprovechamiento de los mercados y de la capacidad competitiva de ambos países en corrientes de intercambio regional y mundial.
} 
y no tarifarios al comercio de bienes y servicios y la armonización de políticas macroeconómicas. Y un año después (1989) comenzó a cobrar importancia la idea de la integración planteada en términos regionales, produciéndose el acercamiento con el gobierno de Uruguay, dando inicio al proceso de integración tripartito que se regiría por los principios de gradualismo, flexibilidad y equilibrio, propio del cambio de modelo que rigió en América Latina en el marco de la ALADI (a partir de 1980).

El año 1990 comenzó siendo un año de cambios de coyunturas políticas regionales e internacionales que impactaron sensiblemente en el paradigma de la integración, de modo tal que en el Acta de Buenos Aires los presidentes de Argentina, Carlos S. Menem y de Brasil, Fernando Collor de Mello, modificaron las pautas del tratado de 1988 (restringiéndolas a lo comercial e intergubernamental) y acordaron "establecer un Mercado Común entre Argentina y Brasil, que debería quedar conformado el 31 de diciembre de 1994", fórmula que se plasmó intacta en el posterior Tratado de Asunción. En este sentido, no podemos negar el viraje de este "nuevo" modelo de integración de corte más comercialista que se diferenciaba del anterior (desarrollista).

Ahora bien, como ha sido analizado por varios autores (Caetano, 2009, 2021; Botto, 2015; Briceño Ruiz, 2015; Bogado Bordazar, 2020), los antecedentes del tratado de Asunción demostraron amplia vocación integracionista y se basaron en el concepto teórico de regionalismo, el cual implica la reunión de un limitado número de Estados ligados geográficamente y con un alto grado de interdependencia entre ellos. También puede ser entendido como un subsistema del sistema internacional. Esta región se caracteriza por su proximidad geográfica, su interrelación económica y social y por su homogeneidad (en el caso de América Latina sería compartir una historia común, lenguaje y costumbre similares, entre otros) (Oyarzún Serrano, 2008). A esta idea se le suma el concepto de cooperación multidimensional que ya había sido acuñado por los distintos estados desde las primeras décadas de la integración. Afirmamos entonces que el integracionismo no se agotó en la variable económica, por el contrario, se orientó hacia la regulación de distintos aspectos de la vida de la región y a la conformación de alianzas y agrupamientos voluntarios de Estados.

\section{1991: año clave}

Hasta acá hemos analizado los años previos al inicio de la vida del tratado de Asunción, en los cuales -como vimos- se desarrollaron varias iniciativas bilaterales de integración que se plasmaron luego en el espíritu mismo del tratado. Sin embargo, en 1991 se profundizaron los cambios coyunturales económicos y políticos y de paradigmas en la región y en el sistema internacional, los cuales también se vieron reflejados en la toma de decisiones y en la composición orgánica del primer esquema de Mercosur, "que apostaba fundamentalmente a objetivos comerciales, con una institucionalidad intergubernamentalista y de baja intensidad que le eran funcionales a los estados" (Caetano Hargain, 2021). Con estas bases se sumaron al encuentro bilateral de Argentina y Brasil, los dos países menores del Mercosur: Uruguay y Paraguay, conformando el bloque con una impronta que se distanciaba bastante de la idea original desarrollista que se había plasmado en el Acta de Foz de Iguazú.

La euforia que imperaba en los sectores de la "alta política", en los ministerios de economía y en los cuerpos diplomáticos de las cancillerías en los meses previos a la firma del Tratado, revelaba la intensidad que habían tenido las discusiones, intercambios y negociaciones generadas para llegar a esa instancia. Vale recordar que fue muy escasa la participación en el proceso preparativo que tuvieron los sectores académicos de los diferentes estados, lo cual refuerza la idea de que en la toma de decisiones estratégicas y que comprometen el futuro de las sociedades, participan grupos restringidos de poder, con parciales análisis de causas y efectos y restringida planificación a mediano y largo plazo.

Sin embargo, en la relectura de los objetivos del Tratado advertimos que determinados sectores no pudieron abandonar la idea de la integración regional como proyecto de desarrollo conjunto, y en este sentido, en los considerandos del texto se estableció que: "la ampliación de las dimensiones de los mercados nacionales, a través de la integración, constituye condición fundamental para acelerar sus procesos de desarrollo económico con justicia social". Lo cual implicaba -entre otras cuestiones- "que ese objetivo se alcanzaría mediante 
el más eficaz aprovechamiento de los recursos disponibles, la preservación del medio ambiente, el mejoramiento de las interconexiones físicas, la coordinación de las políticas macroeconómicas y la complementación de los diferentes sectores de la economía, con base en los principios de gradualidad, flexibilidad y equilibrio". Pero además se pensó a la integración como una respuesta adecuada a la evolución de los acontecimientos internacionales, teniendo en cuenta la existencia de grandes espacios económicos y la importancia de lograr una adecuada inserción internacional para los países integrantes. Esto último lo vamos a ver claramente en la dimensión sobre el relacionamiento externo del Mercosur.

De manera tal que el Tratado de Asunción se redactó fusionando los objetivos antes descriptos y los postulados de la teoría de la integración económica, con lo cual se acordó ya en sus primeras líneas la conformación de un mercado común y se definieron sus implicancias (libre circulación de bienes, servicios y factores productivos entre los países; establecimiento de un arancel externo común y la adopción de una política comercial común con relación a terceros Estados y la coordinación de posiciones en foros económico comerciales regionales e internacionales; la coordinación de políticas macroeconómicas y sectoriales y; el compromiso de los Estados Partes de armonizar sus legislaciones internas para fortalecer el proceso de integración) ${ }^{6}$.

Los Estados establecieron en el mismo Tratado que las medidas descriptas (artículo 1) debían consolidarse en diciembre de 1994, habilitando de esta manera un período de transición que desde el inicio se consideró muy ambicioso y difícil de cumplir. Sin embargo, los Estados Partes acordaron, poner en marcha diversos mecanismos de integración como: el Régimen General de Origen, el Sistema de Solución de Controversias, las Cláusulas de Salvaguardia, un Programa de Liberalización Comercial y la Coordinación de Políticas Macroeconómicas, así como también el establecimiento de un Arancel Externo Común (AEC). Todos estos mecanismos fueron implementados en textos anexos al Tratado y fueron consideradas medidas necesarias para avanzar hacia la conformación de la unión aduanera primero y del mercado común con posterioridad. Muchos de los cuales fueron efectivamente implementados, como veremos posteriormente.

\section{El Tratado de Asunción y el despliegue de sus múltiples dimensiones}

En este apartado proponemos un recorrido por las múltiples dimensiones que fueron surgiendo a partir de los postulados del Tratado de Asunción a lo largo de los treinta años de historia y que, a nuestro criterio, refuerzan la idea de que la integración regional no se ha agotado en la variable económica y comercial, siendo éste el fundamento de su perdurabilidad.

\section{a. La dimensión comercial}

Sin perjuicio de lo afirmado en el párrafo anterior, el primer objetivo plasmado en el Tratado fue "ampliar la dimensión de los mercados nacionales" "7 a través de la integración regional, lo cual implicaba, la conformación del mercado común y la consecuente eliminación de los derechos aduaneros y restricciones no arancelarias a la circulación de mercaderías (artículo 1). Por lo tanto, la inmediata implementación de estas medidas -muchas de las cuales ya habían sido desarrolladas en otros mecanismos bilaterales de la ALADI- dinamizaron rápidamente los intercambios de bienes y servicios en la región, logrando el crecimiento productivo de los mercados y generando algunos proyectos conjuntos.

Asimismo, en el período de transición (1991-1994) se fueron aprobando normas, definiendo cronogramas y creando grupos de trabajo para agilizar el andamiaje del mercado común. En 1992 se firmó el primer cronograma de medidas que debían adoptarse según lo establecido en el Tratad de Asunción para constituir el mercado común al 31 de diciembre de 1994, conocido como: Cronograma de Las leñas ${ }^{8}$. En esta norma se definieron los primeros subgrupos de trabajo que se encargaron de abordar las diferentes temáticas y gestionar

\footnotetext{
${ }^{6}$ Artículo 1 Tratado de Asunción.

${ }^{7}$ Surge del considerando del Tratado de Asunción.

${ }^{8}$ Decisión CMC 01/92
} 
las medidas acordes a los fines arriba enunciados. Los grupos de trabajo fueron: asuntos comerciales, asuntos aduaneros, políticas fiscal y monetaria, normas técnicas, transporte terrestre, transporte marítimo, política industrial y tecnológica, política agrícola, política energética, coordinación de políticas macroeconómicas, relaciones laborales, empleo y seguridad social.

Concretamente en el área comercial el Tratado de Asunción definió al "mercado común" (artículo 1) y además estableció el compromiso de avanzar en cuatro frentes durante el período de transición: el del libre comercio irrestricto, el del arancel externo común ${ }^{9}$, el de la coordinación macro-económica y el de los acuerdos sectoriales ${ }^{10}$. Es importante recordar que al finalizar el período de transición (1994) se celebró el Protocolo de Ouro Preto (POP), el cual si bien significó una continuidad de los objetivos planteados en el Tratado de Asunción introdujo algunas modificaciones, fundamentalmente en lo que tuvo que ver con la extensión de plazos para el perfeccionamiento del programa de liberación comercial (en especial para el sector azucarero y automotriz), el cual como mencionamos anteriormente, se había planteado como extremadamente ambicioso. Además del arancel externo común (con sus listas de excepciones) se tomaron otras medidas: se disciplinaron los incentivos a las exportaciones ${ }^{11}$; se previeron otras medidas para las políticas públicas que distorsionen la competitividad; se aprobó el régimen de origen ${ }^{12}$; se definieron pautas para un régimen de defensa de la competencia y se aprobó el código Aduanero del Mercosur, el cual, hasta la fecha, nunca entró en vigencia. El principal problema es que algunas de estas medidas fueron de cumplimiento restringido o nunca fueron adoptadas (Peña, 2006).

Otra cuestión importante que se definió en Ouro Preto -para armonizar los posibles conflictos normativosfue la derogación de todas las disposiciones del Tratado de Asunción que fueran contrarias a aquella norma y al contenido de las Decisiones aprobadas por el Consejo del Mercado Común durante el período de transición (artículo 53 POP).

Como se dijo anteriormente, en los primeros años de la integración hubo un aumento significativo de los intercambios comerciales entre los cuatro socios del Mercosur, al punto que el comercio intrazona presentó una tasa de expansión anual superior al 26\% en el período 1991-1997 y recién comenzó a registrar su primera caída en el segundo semestre de 1998. Esto se produjo tras varios hechos internacionales que impactaron negativamente en la región, podemos mencionar: la reducción del precio de los commodities, las crisis financieras y cambiarias del Sudeste Asiático y la de Rusia y, posteriormente la devaluación de Brasil (BID-INTAL, 1999), todo lo cual además puso de manifiesto varias inconsistencias del sistema normativo e institucional, que no se adecuaban a la necesaria evolución del proceso de integración y en definitiva a los objetivos dinámicos establecidos en el propio Tratado de Asunción.

\section{b. La dimensión institucional}

Sobre esta dimensión lo primero que tenemos que mencionar es que el Tratado de Asunción legitimó el modelo intergubernamental ${ }^{13}$ de conformación institucional, el cual se ha mantenido básicamente durante los treinta años de existencia del bloque. En este sentido, reconocemos la importancia que tiene el tema ya que

\footnotetext{
${ }^{9}$ De los cuatro ejes mencionados el que se logró plenamente en el período de transición fue el del establecimiento del arancel externo común, al cual posteriormente se le incluyen determinadas listas de excepciones.

${ }^{10}$ Decisión CMC 03/91.

${ }^{11}$ MERCOSUR/CMC/DEC. N ${ }^{o}$ 10/94: Armonización para la aplicación y utilización de incentivos a las exportaciones por parte de los países integrantes del Mercosur.

${ }^{12}$ MERCOSUR/CMC/DEC. N 06/94: Régimen de Origen Mercosur. En función de esta Decisión se aprueba el reglamento correspondiente al régimen de origen.

${ }^{13}$ Lo cual surge de los artículos 9 a 16 del Tratado de Asunción y posteriormente ampliado por el Protocolo de Ouro Preto (1994) al definir la estructura institucional del bloque, su composición y su sistema de adopción de normas.
} 
todas las acciones emanadas del Mercosur recaen o están afectadas por las diferentes instituciones. De hecho las reformas y la creación de órganos nuevos fue una constante en todo el proceso y el debate entre otorgarle más o menos autonomía también estuvo siempre presente. La "supranacionalidad", entendida como cesión de soberanía a los órganos comunitarios, fue otro de los conceptos recurrentes en la reforma institucional pero nunca abordado seriamente por los gobiernos de los socios del bloque. De hecho, las pocas referencias a órganos a los cuales se les había otorgado cierta autonomía institucional, como el Alto Representante General del Mercosur, la Comisión de Representantes Permanentes (CRPM) ${ }^{14}$ o los funcionarios técnicos de la Secretaría del Mercosur o fueron disueltos (como el caso del Alto Representante General ${ }^{15}$ ) o limitados en sus actividades (CRPM y Secretaría).

La estructura orgánica inicial (que emana del Tratado de Asunción) se encargó básicamente de sancionar las normas que le dieron forma al período de transición (1991-1994) y fue modificada por el Protocolo de Ouro Preto en el año 1994. El diseño establecido por el POP reflejó una continuidad política e ideológica del período anterior, es decir con la elección de un modelo de integración mercantilista, basado en un sistema institucional intergubernamental que mantenía la concentración de la toma de decisiones en los poderes ejecutivos nacionales y en particular en determinadas agencias de los gobiernos nacionales (Caetano Hargain, 2009), lo cual se reflejó en el mencionado Protocolo. La toma de decisiones continúa realizándose en todos los casos por consenso y con la presencia de todos los Estados partes -en este punto no hubieron modificaciones en relación al Tratado de Asunción. Sin embargo surgieron algunas instituciones nuevas que fueron demandadas por la propia evolución del proceso de integración, de manera tal que a los órganos con capacidad decisoria (Consejo Mercado Común-CMC y Grupo Mercado Común - $\mathrm{GMC}^{16}$ ) se le sumó la Comisión de Comercio (CCM) y se crearon órganos nuevos sin capacidad de decisión: (i) el Foro Consultivo Económico y Social (FCES), de carácter privado y autónomo que pasa a integrar la estructura institucional del bloque y representa a los sectores económicos y sociales y está integrado por organizaciones empresariales, sindicatos y tercer sector. (ii) A través de este Protocolo se renuevan la Secretaría del Mercosur y la Comisión Parlamentaria Conjunta (CPC), la cual desde su creación en el Tratado de Asunción fue el órgano representativo de los Parlamentos de los Estados partes y se le encargó la tarea de ser el nexo entre los poderes legislativos y ejecutivos de los Estados partes con el objetivo de "facilitar el avance hacia la conformación del Mercado Común" (artículo 24). Actualmente la CPC ha sido sustituida por el Parlamento del Mercosur (Parlasur), órgano que representa la pluralidad ideológica y política de los pueblos de los países miembros, creado el 9 de diciembre de 2005. Es el primer órgano del bloque en el que se toman decisiones sin necesidad de que sean adoptadas por unanimidad o consenso.

Es indudable que el Parlasur es una herramienta sustancial en la institucionalidad del bloque, pues los objetivos plasmados en su Protocolo de creación ${ }^{17}$ se enfocaron en la participación ciudadana y en la democratización del proceso de integración. Pero a la vez se le presentaron desafíos importantes y uno de ellos radica en la necesidad de adquirir liderazgo institucional, con el doble propósito de poner fin al esquema de composición casi exclusivamente intergubernamental de los órganos del Mercosur y en segundo lugar, para que pueda ejercer las funciones propias de un parlamento regional: crear legislación comunitaria. Para esta tarea tendrá que sensibilizar a la ciudadanía, de manera tal de comprometer su participación activa en dicho proceso, ya que, hasta el momento esta función no está contemplada. Por otro lado, su principal labor consiste en fomentar la aprobación de la normativa Mercosur en los parlamentos internos de los Estados Partes y

\footnotetext{
${ }^{14}$ Como se desprende del Tratado de Asunción (luego confirmado en el Protocolo de Ouro Preto) los órganos con capacidad decisoria del Mercosur también están legitimados para crear y suprimir órganos nuevos y reformar las instituciones.

${ }^{15}$ Por Decisión CMC No. 63/10 se había creado el cargo de Alto Representante General del Mercosur, como órgano del CMC, con las siguientes funciones: presentar propuestas vinculadas al proceso de integración; asesorar al CMC; coordinar los trabajos relativos al Plan de Acción para el Estatuto de ciudadanía del Mercosur; representar al Mercosur por mandato expreso del CMC; mantener diálogo con otros órganos del bloque; participar en misiones de observación electorales solicitadas por el Mercosur; entre otras. Y por Decisión CMC No. 05/17 fue suprimido el cargo.

${ }^{16}$ Estos dos órganos ya habían sido contemplados en el Tratado de Asunción (1991).

${ }^{17}$ Decisión CMC/23/2005, Protocolo Constitutivo del Parlamento del MERCOSUR.
} 
realizar el "control" sobre los otros órganos del bloque. Funciones que en algunos momentos se han visto muy limitadas y que fueron heredadas del propio Tratado de Asunción.

Podríamos afirmar que en el transcurso de los años se fueron atendiendo a los diferentes déficits institucionales, sin embargo las dificultades y carencias se manifestaron en la credibilidad hacia las mismas. El problema en el Mercosur no es la falta de instituciones, sino la ausencia de convergencia que existe entre ellas, lo que deriva necesariamente en la desorganización de la normativa institucional. Como es sabido, la metodología aprobada para sancionar normas primarias y secundarias no ha sido eficiente y ha generado un sinnúmero de normativas y reglamentaciones muchas de las cuales no son aplicadas por los Estados o lo hacen en forma deficiente, lo cual genera las consecuentes controversias difíciles de resolver y un desarrollo normativo caótico (BID-INTAL, 2004). Esta carencia se arrastra desde el Tratado de Asunción. En varias oportunidades se ha pensado en una reforma institucional integral del Mercosur que contemple los diferentes déficits mencionados, sin embargo el freno se ha ubicado siempre en el mismo lugar: la decisión política de otorgar mayor autonomía decisoria a los órganos del Mercosur y a la vez reglamentar, es decir definir y acordar regionalmente, el valor jurídico y la obligatoriedad que tendrán las normas emanadas de esos órganos en todos los Estados por igual ${ }^{18}$. Hasta que ambas cosas no ocurran seguirá siendo compleja la profundización y evolución del proceso de integración como tal y la integral aplicación del Tratado de Asunción.

\section{c. La dimensión de la solución de controversias}

Como esbozamos en el apartado anterior una de las dificultades recurrentes que se presentaron en todos estos años de integración han sido los diferentes conflictos devenidos del programa de liberalización comercial y de la aplicación de reglas de origen ${ }^{19}$ y por ende, la consecuente solución de las controversias. En este sentido, ya el Tratado de Asunción en su Anexo (III) había estructurado una primera versión provisoria. La misma fue rápidamente revisada en el Protocolo de Brasilia de 1991, complementada en el Protocolo de Ouro Preto (1994) y finalmente redefinida en el Protocolo de Olivos $(2002)^{20}$, el cual organiza todo el procedimiento y crea el Tribunal Permanente de Revisión del Mercosur (TPRM) ${ }^{21}$. De esta manera la actividad de los tribunales arbitrales Ad hoc (creados en el Protocolo de Brasilia), se complementan con un Tribunal Permanente, generando -entre otras innovaciones- la posibilidad de revisión de los laudos emitidos por los tribunales Ad hoc, una vez que se sometan al TPRM.

Destacamos la innovación de haberle otorgado al TPRM la doble competencia contenciosa, pues atiende reclamos efectuados por los Estados y particulares realizados contra un Estado miembro del bloque por incumplimiento de las normas del Mercosur y también la competencia consultiva, a la cual pueden recurrir los demás órganos del bloque. Sin perjuicio de la existencia de este sistema de solución de controversias, es necesario mencionar que se ha recurrido muy poco al mismo, ya que los Estados en general han preferido utilizar mecanismos informales y/o diplomáticos y no judiciales para solucionar sus diferencias comerciales, lo cual provoca escasa credibilidad en el sistema y en sus instituciones. Esta idea se desprende del perfil presidencialista que ha caracterizado a los diferentes gobiernos de la sub región y también es producto del carácter intergubernamental del sistema institucional surgido de Asunción.

\footnotetext{
${ }^{18}$ Las constituciones nacionales de los países miembros del Mercosur, no tienen definido con claridad el status jurídico de las normas obligatorias dictadas por los organismos decisorios del bloque, ni sus condiciones de validez interna en cada estado. En la práctica cada país ha elaborado procedimientos que permitan una rápida incorporación de las normas del Mercosur como derecho interno. Esto nos lleva a sostener que el derecho "mercosureño" no tenga aún la condición de derecho comunitario.

${ }^{19}$ Que surgen del objetivo de integración económica del Tratado de Asunción.

${ }^{20}$ En el año 2000 el Consejo del Mercado Común (CMC) creó un Grupo de Alto Nivel (GAN) para que estudie las dificultades del sistema de solución de controversias vigente y eventualmente elabore un proyecto. Sobre la base de ese proyecto se firmó en febrero de 2002 el Protocolo de Olivos sobre Solución de Controversias creando el Tribunal Permanente de Revisión (TPRM).

${ }^{21}$ El CMC aprobó su reglamento en el año 2003, en el año 2004 el mismo quedó constituido, para iniciar sus actividades el 18 de agosto de 2004. Su sede se encuentra en Asunción.
} 


\section{d. La dimensión democrática}

El compromiso con la democracia fue uno de los fundamentos que estuvo presente en el Mercosur desde sus inicios. Fue a partir de que los cuatro países del bloque retomaran los caminos democráticos que se pudo dar lugar a este "encuentro". Antes -con los gobiernos ilegítimos- habría sido imposible. Podemos afirmar entonces que el tema fue abordado como una constante e incorporado al plexo normativo del Mercosur desde los orígenes, constituyendo la variable democrática un requisito incuestionable e irrenunciable en el proceso de integración. En el Tratado de Asunción no está expresamente definida esta dimensión, sin embargo se desprende de los considerandos del mismo cuando expresa por ejemplo que: "la ampliación de las actuales condiciones de sus mercados nacionales, a través de la integración, constituye condición fundamental para acelerar sus procesos de desarrollo económico con justicia social" o "el presente Tratado debe ser considerado como un nuevo avance en el esfuerzo tendiente al desarrollo en forma progresiva de la integración de América Latina". Todo lo cual puede ser posible únicamente en el marco de gobiernos democráticos.

El déficit que presentaba el Tratado de Asunción en este sentido se vio complementado básicamente en dos instrumentos: (i) el Protocolo sobre compromiso democrático del Mercosur, la República de Bolivia y la República de Chile (firmado en Ushuaia en 1998), el cual establece en su artículo 1: "la plena vigencia de las instituciones democráticas es condición esencial para el desarrollo de los procesos de integración entre los Estados Parte" y continúa más adelante diciendo que los Estados promoverán las consultas pertinentes entre sí y con el Estado afectado y considerarán la naturaleza y el alcance de las medidas a aplicar, teniendo en cuenta la gravedad de la situación existente. Dichas medidas abarcarán desde la suspensión del derecho a participar en los distintos órganos de los respectivos procesos de integración, hasta la suspensión de los derechos y obligaciones emergentes de esos procesos (artículos 4 y 5). (ii) Por otro lado, el Protocolo adicional sobre compromiso con la democracia firmado en Montevideo (2011), contiene normas fundamentales para la preservación del orden democrático en los países miembros. Señala que sus disposiciones se aplicarán "en caso de ruptura o amenaza del orden democrático" en un Estado Parte y detalla cuales son los procedimientos aplicables, tales como las consultas y gestiones que se promoverán entre los miembros del bloque y el país afectado con vistas a buscar el restablecimiento del orden democrático, hasta el cierre total o parcial de fronteras, limitar el tráfico aéreo y marítimo, las comunicaciones, la provisión de energía, servicios y suministros, estableciendo asimismo la posibilidad de adoptar sanciones políticas y diplomáticas adicionales (Art. 6).

En referencia a la aplicación de estos protocolos, recordamos que el año 2012 para el Mercosur fue uno de los años más complejos políticamente por la suspensión de Paraguay de su participación en los órganos decisorios del bloque, tras el golpe institucional o parlamentario contra el Presidente Fernando Lugo, quien fue sometido a juicio político tras la masacre de Curuguaty. Situación que fue revertida al año siguiente luego de que se realizaron elecciones democráticas en el país. Asimismo, cabe destacar que en el año 2017 se suspendió a Venezuela en todos los derechos y obligaciones inherentes a su condición de Estado Parte del Mercosur, tras las consultas realizadas entre los Cancilleres de los Estados Partes (artículo $5^{\circ}$ del Protocolo de Ushuaia). Ahora bien, así como afirmamos que es incuestionable que nuestro proceso de integración se fundamente en el compromiso democrático, en oportunidades esta condición no ha sido discutida, lo que ha revelado situaciones de falta de compromiso manifiesto con la "democracia declarada". A modo de ejemplo mencionamos el caso del controvertido impeachment realizado a la ex presidenta de Brasil, Dilma Roussef (2016) o el golpe de estado contra el presidente de Bolivia, Evo Morales en 2018, oportunidades en las cuales las manifestaciones de los socios han sido ambiguas y los instrumentos jurídicos con los que cuenta el bloque no fueron aplicados.

El Mercosur no ha sido ajeno a la crisis que atraviesa la democracia -como sistema político- en toda la región latinoamericana. En América latina se ha reflejado en los últimos años una insatisfacción muy amplia con la democracia. En este sentido, mencionamos el último informe de Latinobarómetro (2018), el cual concluye que; "la crisis de la democracia se refleja muy bien en este indicador de desempeño donde aumentan de un 51\% en 2008 a 71\% en 2018 los insatisfechos, una década de disminución constante y continua de satisfacción con la democracia". A modo de ejemplo; Brasil fue uno de los países de la región del Mercosur donde más se redujo la satisfacción con la democracia, solo el 9\% estaría satisfecho, asimismo, sólo el 34\% 
la apoya y el $41 \%$ es indiferente hacia ella. A su vez es un país donde un $73 \%$ de ciudadanos no vota por partido, sino que se inclinaría por elegir un candidato que se ubica afuera del establishment rompiendo con todo lo establecido, siendo este fenómeno de larga data en el país (Latinobarómetro, 2018).

\section{e. La dimensión social y solidaria}

Como dijimos, los procesos de integración regionales no se agotan en la variable económica, sino que regulan distintos aspectos de la vida de la región. En este sentido, es importante mencionar que los Estados del Mercosur en algún momento tuvieron la voluntad de rebasar la fase de libre comercio (modelo economicista) que imperaba en el Tratado de Asunción, para profundizar otra dimensión: la social. Para autores como Helio Jaguaribe (1967, citado en Lorenzini, 2014), la dimensión política y social, toma en consideración el grado de integración sociocultural, el nivel moral y educacional de la población: la forma en la que se vinculan las distintas clases sociales, la participación y el nivel de representatividad social en el sistema político, el acceso a los servicios públicos básicos como la educación y la salud, entre los más relevantes. Pero afirma que todos los niveles deben estar vinculados entre sí para lograr el desarrollo multidimensional de la sociedad (Jaguaribe, 1967, citado en Lorenzini, 2014). De manera tal que para alcanzar este nivel "superior" de integración, los Estados han tenido que generar nuevas estrategias e incorporar temas y sustentarlos en instrumentos jurídicos, que no habían sido antes analizados en la agenda de integración.

La participación de varios sectores de la sociedad civil en el proceso de integración impactó en la promoción del modelo social del Mercosur, a la vez que los órganos del bloque concentraron sus estrategias hacia la creación de nuevas estructuras, marcos teóricos y estrategias de diálogo que fueron dando cabida a estos grupos y a los nuevos temas. A modo de ejemplo podemos mencionar la creación del Instituto Social del Mercosur (ISM), desde donde se elaboró un documento denominado la "Dimensión social del Mercosur, Marco conceptual" o la Reunión de Ministros y Autoridades de Desarrollo Social del Mercosur y Estados Asociados (RMADS), que elaboró la "Declaración de Principios del Mercosur Social". Desde ambos órganos se comenzó a discutir el concepto de "ciudadanía" asociado a la idea de "participación real" del individuo y de los grupos sociales en las esferas regionales, con la necesidad de dotar de legitimidad al proceso de integración y generar una "identidad regional" (ISM, 2012):

(...) el Mercosur debe ser un espacio donde converjan las demandas de una ciudadanía cada vez más participativa, más consciente de sus derechos, deberes y obligaciones, pero por sobre todas las cosas, consciente de su pertenencia al espacio mayor de contención, conformando la conciencia regional que el proceso de integración demanda en esta instancia (Declaración de Principios del Mercosur Social, 2007).

Asimismo, en la práctica también se realizaron manifestaciones desde los diferentes ámbitos de reunión del bloque a favor de la profundización de la dimensión social, a saber:

(...) todos los Estados Miembros y Asociados del Mercosur estamos comprometidos en la tarea ineludible de forjar un presente de dignidad para nuestros pueblos. Los diversos Planes y Programas que atienden las condiciones en que se hallan - aún hoy - miles de ciudadanos y ciudadanas, corroboran el sentido de una renovada práctica institucional que coloca el acento en la impostergable función de integración social a través de múltiples modalidades y dispositivos de asistencia pública y promoción social"22.

Ahora bien, la construcción teórica del "Mercosur social" que puso el acento en la profundización de la integración regional y el cambio de paradigma en los distintos países sobre cómo abordar "la cuestión social", dio como resultado la aprobación de normas, de planes y programas sociales que comenzaron a diseñarse a partir de los primeros años del nuevo milenio. Son varios los autores que coinciden en que hubo un verdadero

\footnotetext{
${ }^{22}$ Declaración de Principios del Mercosur Social (RMADS) de 2007. Cabe destacar que el Tratado de Asunción (artículo 12) prevé la posibilidad de que el Consejo Mercado Común, órgano político del bloque, invite a participar de las reuniones a otros ministros o autoridades de nivel ministerial, lo cual se realizó desde el principio y fue generando una participación amplia de otros sectores gubernamentales.
} 
cambio de época en la región y sobre todo en la relación entre Brasil y Argentina (Gomez Saraiva, 2012; Simonoff, 2009; Merino, 2018; Actis, 2016; Miranda, 2015) y sin duda la novedad, en materia política, fue la puesta en marcha de un nuevo enfoque denominado "solidaridad regional" que se tradujo en la consolidación del modelo social de integración del Mercosur, que incluyó en la agenda regional proyectos como el Fondo de Convergencia Estructural del Mercosur (FOCEM), libre circulación de personas, estatuto de ciudadanía y agricultura familiar, entre otros (Bogado Bordazar, 2021).

Podemos afirmar entonces que los fundamentos del Tratado de Asunción se despliegan en esta etapa para profundizar el regionalismo y el desarrollo. Esto fue posible a partir de las prerrogativas que tanto el Tratado de Asunción como el Protocolo de Ouro Preto le asignaron al Consejo Mercado Común como órgano político y coordinador del desarrollo del proceso de integración. En este sentido hemos visto como se construyó el espacio de las Cumbres Sociales del Mercosur que reunió desde el año 2006 a más de 500 Organizaciones No Gubernamentales (ONG) de todos los países del bloque y que, organizadamente llevaron propuestas a la Cumbre del CMC. Se reconoce el amplio alcance de estos espacios de carácter pluriparticipativos que contribuyen a afianzar la constante necesidad de diálogo con los sectores y movimientos sociales para la construcción de un Mercosur más amplio ${ }^{23}$.

Asimismo, se ha abordado la cuestión migratoria a través del paradigma del "desarrollo" y se avanzó en la elaboración de políticas migratorias regionales con el objetivo último de generar un espacio de libre circulación de personas intrarregional con un alto estándar de protección de los derechos humanos ${ }^{24}$ de los migrantes, ponderando a la migración como un derecho humano y reconociendo la sinergia entre el nivel sudamericano y subregional (Bogado Bordazar, 2021). Estas políticas comenzaron a construirse a través de los diálogos interinstitucionales en el Foro Especializado Migratorio del Mercosur (FEM) y posteriormente con la aprobación de los Acuerdos de Residencia del Mercosur y Estados Asociados (2002). En la misma línea se aprobaron programas como el Estatuto de Ciudadanía del Mercosur ${ }^{25}$ con el fin de profundizar la dimensión ciudadana del bloque y consolidar los derechos y garantías fundamentales de los ciudadanos ${ }^{26}$ o, el Plan Estratégico de Acción Social ${ }^{27}$. En los fundamentos de las normas mencionadas los Estados afirman la necesidad de avanzar en la "profundización de la dimensión social y ciudadana del proceso de integración, con miras a alcanzar un desarrollo sustentable, con justicia e inclusión social y a garantizar a los nacionales de los Estados parte y a sus familias el goce de los mismos derechos y libertades civiles, sociales, culturales y económicas" 28 .

El modelo social de integración también tuvo sus expresiones en la consolidación del Fondo de Convergencia Estructural del Mercosur $\left(\right.$ FOCEM $^{29}$ ), el cual fue creado como fondo solidario para la financiación de proyectos nacionales y regionales que apuntaran a las áreas de convergencia estructural (obras de infraestructura), cohesión social (promoción e inclusión social), desarrollo de la competitividad (cadenas de valor, mecanismos en sectores productivos) y fortalecimiento de la estructura institucional y del proceso de integración, con capitales constituidos por el Mercosur. Este instrumento fue uno de los más destacados del bloque

\footnotetext{
${ }^{23}$ Expresado en el Comunicado Conjunto de los Presidentes de los Estados Partes del Mercosur en oportunidad de la XXXVII Reunión Ordinaria del Consejo Mercado Común, Asunción, 23 y 24 de julio 2009.

${ }^{24}$ También destacamos la labor del Instituto de Políticas Públicas de Derechos Humanos del Mercosur, creado por Dec. CMC No. $14 / 09$.

${ }^{25}$ Dec. CMC No. 64/10 (modificada por la Dec. 32/17).

${ }^{26}$ El Estatuto de Ciudadanía del Mercosur y el Plan de Acción para la conformación progresiva de dicho Estatuto (Dec. CMC 64/10), según lo establecido en la propia norma, tenían que a estar implementados al cumplirse el trigésimo aniversario de la firma del Tratado de Asunción (2021), cuestión que no se llegó a concluir en su totalidad.

${ }^{27}$ Dec. CMC No. 67/10 y aprobado por Dec. CMC No. 12/11.

${ }^{28}$ MERCOSUR/CMC/DEC No. 64/10. Anexo No. 2.

${ }^{29}$ Dec. CMC 05/05.
} 
como generador de políticas públicas regionales orientadas a asistir a las regiones más postergadas de los socios menores: Paraguay y Uruguay, quienes reclamaron legítimamente algún tratamiento de las asimetrías en el bloque. El fundamento jurídico del reconocimiento de asimetrías en el bloque nos remite al artículo 6 del Tratado de Asunción, en el cual se expresaba lo siguiente: "los estados partes reconocen las diferencias puntuales de ritmo para la República del Paraguay y para la República Oriental del Uruguay”.

Ahora bien en todas estas políticas que surgieron en función del modelo social de integración ${ }^{30}$ se produjeron sinergias y coincidencias entre los diferentes gobiernos del Mercosur que hicieron posible su creación, sin embargo en algunos momentos se percibieron dificultades para la implementación de las normas y programas, lo cual -a nuestro juicio- es producto de la fragilidad de las instituciones y de las dificultades para la implementación de las normas comunitarias. Esto explica en parte los motivos de la "paralización" que por momentos sufren de los proyectos y programas del Mercosur.

\section{f. La dimensión externa}

El Tratado de Asunción también previó la posibilidad de la incorporación de nuevos miembros, tanto de la ALADI como de otras regiones (artículo 20). Así fue como el Mercosur logró visibilidad regional e internacional a lo largo de estos años, gestionando acuerdos de cooperación con otros Estados y acuerdos de asociación con otros bloques de integración. La agenda externa ha sido muy dinámica. Asimismo, el bloque supo consolidar posiciones comunes en diversos foros internacionales y multilaterales (Naciones Unidas, Fondo Monetario Internacional o Banco Mundial).

Así fue como finalizada la etapa de transición (1991 a 1994), el Mercosur comenzó a trabajar en la "nueva imagen de la integración" la cual tuvo como objetivo la apertura en dos ejes bien definidos: hacia los países de América Latina y hacia el resto del mundo. En el primer caso, el proceso se inició en 1995 con la incorporación de Chile y Bolivia como países asociados al bloque, lo cual significó el inicio de la proyección de la frontera hacia los vecinos sudamericanos, construyendo de esta manera, un espacio de "integración ampliada". Este espacio se complementó posteriormente con la incorporación de Perú como Estado Asociado y la firma de una zona de libre comercio con la Comunidad Andina de Naciones (CAN). No podemos dejar de mencionar el impulso que le dieron los países del Mercosur a la integración sudamericana, al suscribir la Declaración de Cuzco (2004), a partir de la cual comenzó a gestarse el proyecto de Comunidad Sudamericana de Naciones (CSN), transformada en el año 2008 en la Unión de Naciones Sudamericanas (Unasur).

En el año 2005 se aprobó el Protocolo de Adhesión de Venezuela al Mercosur (artículo 20), representando un nuevo desafío para el proceso de integración, ya que implicaba la adaptación de los instrumentos de la política comercial externa venezolana al arancel externo común y la coordinación de las políticas macroeconómicas y sectoriales, así como la gradual incorporación por parte de Venezuela de la normativa Mercosur a su ordenamiento interno. Desafío que Venezuela no pudo cumplir en su totalidad y que fue uno de los argumentos esgrimidos para acelerar el proceso de suspensión.

En el segundo eje de relacionamiento externo, el Mercosur se vinculó con otros bloques extrarregionales ${ }^{31}$, como la Unión Europea (UE), con quien finalmente celebró el acuerdo de Asociación Estratégica en 2019. Como sabemos, este acuerdo se estuvo negociando por más de veinte años y ha generado muchos desencuentros políticos y de estrategias comerciales en el ámbito del Mercosur. Aún queda un largo camino por recorrer ya que la puesta en funcionamiento requerirá de la aprobación parlamentaria del mismo en ambos bloques. Otro tema que se está discutiendo en profundidad desde Europa es la cuestión ambiental y en este sentido el Mercosur en sus años de historia aún no ha promovido una seria discusión regional sobre el tema. Es uno de los grandes déficits del Mercosur y de la región sudamericana en su conjunto.

\footnotetext{
${ }^{30}$ Podríamos mencionar también los programas de Mercosur Educativo impulsado por la Reunión de Ministros de Educación; el Mercosur Cultural o el programa "Mercociudades", entre otros.

${ }^{31}$ En los propios considerandos del Tratado de Asunción, se establece que, como forma de lograr una adecuada inserción internacional será importante hacer un buen análisis de la consolidación de los grandes espacios económicos.
} 
Las dinámicas de las relaciones comerciales internacionales también han generado vinculaciones del Mercosur con otros países y espacios en la búsqueda de nuevos socios, a saber: la República Popular China, Egipto, Sudáfrica, Israel, Canadá y con los países del Consejo de Cooperación del Golfo, con quienes se encuentra en etapas de negociaciones para concretar acuerdos marco de cooperación o zonas de libre comercio.

\section{Algunas reflexiones}

Una primera reflexión, nos lleva a afirmar que el Tratado de Asunción ha sido mucho más que un simple tratado. Muy a pesar de las predecibles voces disidentes y las apuestas en contrario, se ha constituido como un gran instrumento jurídico desde donde se gestó un proyecto concreto; imaginado, reflexionado, escrito y gestionado por muchos protagonistas de nuestra historia regional, que interpretando el devenir de algunos sucesos claves de esa coyuntura, supieron dar origen a una verdadera comunidad de intereses.

La puesta en marcha de las dimensiones desarrolladas a partir del Tratado de Asunción, explican la existencia del "gran proyecto de integración" en lo social, cultural, educativo, en la libre circulación de las personas, en la promoción de los derechos humanos y derechos laborales, entre otros. Cabe mencionar que este proyecto ha tenido avances conjuntos en todos estos años. Sin embargo, aún quedan muchos objetivos por cumplir y no menos desafíos por enfrentar.

Y al mismo tiempo que mencionamos algunos de estos logros y éxitos en los 30 años transcurridos, también debemos incorporar en nuestro análisis las dificultades del Mercosur. Ya hemos visto como el devenir del bloque ha transitado por muchas etapas, poniendo en práctica distintos modelos de integración, que trascendieron las bases fundamentalmente económicas del Tratado de Asunción, los cuales aún siguen en discusión. Sin embargo, podríamos afirmar que en la actualidad estamos en un punto de estancamiento, donde las pujas políticas, los individualismos y los vertiginosos cambios en la dinámica geopolítica internacional siguen "perforando el proceso de integración" y desviando el objetivo central del bloque, que es el de promover el desarrollo democrático con justicia social a través de la cooperación integral entre sus socios.

El Mercosur transita una etapa en la cual los Estados están restando "acción colectiva" para privilegiar una participación individual con otros países o bloques de poder en el ámbito internacional. La bilateralidad parece superponerse a la regionalización y al unionismo en América Latina. Estamos en un momento de reconfiguraciones en varios niveles: internacional, regional y nacional y esto nos obliga a reconstruir algunos aspectos de nuestro contrato regional, donde se potencie la diversidad cultural y el interés superior de los pueblos. Esto a su vez le proporcionaría al proceso de integración un fuerte incremento en el componente de legitimidad desde todos los sectores sociales. Quizás éste sí sea el momento de repensar el modelo de la integración. Hasta aquí la región no se había enfrentado a una pandemia de las características que está provocando la COVID-19, que como ya vimos afectó por igual hemisferios y regiones.

Nuestro principal desafío estaría orientado entonces a la profundización de todas las dimensiones desplegadas por el Tratado de Asunción, añadiéndole además el desarrollo de estrategias en una dimensión escasamente trabajada en el Mercosur: la gestión de crisis multidimensionales de impacto regional. En síntesis, el Tratado de Asunción ha demostrado ser una herramienta jurídica muy sólida para dar inicio al proceso de integración, sin embargo -como hemos analizado- el mismo ha tenido que ser complementado por otros protocolos, declaraciones, decisiones, y programas con el objetivo de ampliar y profundizar el proyecto regional conjunto y como dice el propio texto del tratado "con el fin de mejorar las condiciones de vida de sus habitantes".

\section{Referencias bibliográficas}

Actis, E. (2016). Dilemas y contradicciones de la política sudamericana de Brasil bajo los gobiernos de «Lula» da Silva (2003-2010). Estudios Internacionales, 48(184), 9-37.

https://doi.org/10.5354/0719-3769.2016.42566 
BID-INTAL (1999). Informe Mercosur 1998-1999. https://publications.iadb.org/publications/spanish/document/Informe-MERCOSUR-No-5-(1998-1999).pdf

BID-INTAL (2004). Mercosur: en busca de una nueva agenda. Informe del Relator Andrew Crawley. https://publications.iadb.org/publications/spanish/document/MERCOSUR-En-Busca-de-unaNueva-Agenda.pdf

Bogado Bordazar, L. (2020). Integracionismo. Devés, E. y Álvarez, S. (Eds.), Problemáticas internacionales y mundiales desde el pensamiento latinoamericano. Teorías. Escuelas. Conceptos. Doctrinas. Figuras. Ariadna Ediciones.

Bogado Bordazar, L. (2021). Migraciones en el Mercosur. Hacia la conformación de un modelo de integración regional [Tesis de Doctorado en Relaciones Internacionales, Universidad Nacional de La Plata] http://sedici.unlp.edu.ar/handle/10915/123139

Botto, M. (2015), La integración regional en América Latina: quo vadis? El Mercosur desde una perspectiva sectorial y comparada. Eudeba.

Briceño Ruiz, J. (2015). Saber y teoría: reconstruyendo la tradición autonómica en los estudios de integración en América Latina. Briceño Ruiz, J. y Simonoff, A. (editores), Integración y cooperación regional en América Latina. Una relectura a partir de la teoría de la autonomía. Biblos.

Caetano Hargain, G. (2009). Dimensión institucional de los procesos de integración regional: retos de innovación a cuatro décadas de la firma del "Tratado de la Cuenca del Plata; (1969-2009) Parte I. Relaciones Internacionales, 18(37). https://revistas.unlp.edu.ar/RRII-IRI/article/view/1312

Caetano Hargain, G. (2021). El "primer Mercosur" y la "flexibilización”. Antecedentes útiles para la reflexión (1991-2001). Relaciones Internacionales, 30(60), 124.

https://doi.org/10.24215/23142766e124

Gómez Saraiva, M. (2009). Brasil, entre la Unasur y el Mercosur. Umbrales de América del Sur, No. 9 , Buenos Aires, Argentina.

Instituto Social del Mercosur (2012). La dimensión social del Mercosur. Marco conceptual, RMADS, Mercosur.

Latinobarómetro (2018). Informe Corporación Latinobarómetro 2018, Santiago de Chile. endircuentas.org/recurso/latinobarometro-2018/

Lorenzini, M. (2014). Pensando desde el Sur: ideas, aportes y contribuciones teórico- conceptuales de Hélio Jaguaribe para comprender las realidades latinoamericanas. Simonoff, A. (Comp.), Pensadores del Cono Sur. Los aportes de Jaguaribe, Methol Ferré, Puig y Tomassini a las Relaciones Internacionales, Instituto de Relaciones Internacionales, UNLP.

Merino, G. (2017). Proyectos estratégicos e integración regional en América Latina. El surgimiento de la Alianza del Pacífico, el fortalecimiento del regionalismo abierto y el retroceso del regionalismo autónomo. Relaciones Internacionales, 26(52), 008. https://doi.org/10.24215/23142766e008

Miranda, R. (2015). Internacionalismo etnocéntrico. Las relaciones internacionales de Argentina como potencia media. Relaciones Internacionales, 24(49). https://revistas.unlp.edu.ar/RRII-IRI/arti$\underline{\text { cle/view/2392 }}$

Oyarzún Serrano, L. (2008). Sobre la naturaleza de la integración regional: teorías y debates. Revista de Ciencia Politica, 28(3), 95-113. http://ojs.uc.cl/index.php/rcp/article/view/8024

Pávez Rosales, L. (2017). ¿Un Siglo de Concertación y Proyección Regional? Equilibrios de Poder y Procesos de Integración entre Argentina, Brasil y Chile (1915-2015). Documentos de Trabajo No. 
13. Instituto de Relaciones Internacionales, UNLP. https://www.iri.edu.ar/wp-content/uploads/2018/06/doc-trab-13.pdf

Peña, F. (2006). Los grandes objetivos del Mercosur: zona de libre comercio, unión aduanera y mercado común, trabajo presentado en el Seminario "15 anos de MERCOSUL: Avaliação e perspectivas”, Fundação Memorial da América Latina. São Paulo, 27 e 28 de março de 2006.

Simonoff, A. (2009). Regularidades de la Política Exterior de Néstor Kirchner. CONfines de Relaciones Internacionales y Ciencia Política, 5(10), 71-86.

https://www.scielo.org.mx/scielo.php?script=sci_arttext\&pid=S1870-35692009000200006

Simonoff, A. (2014). Pensadores del Cono Sur. Los aportes de Jaguaribe, Methol Ferré, Puig y Tomassini a las Relaciones Internacionales. Documento de Trabajo No. 8 Instituto de Relaciones Internacionales (UNLP). https://www.iri.edu.ar/images/Documentos/documentos/doc_trab_8.pdf

\section{Siglas utilizadas}

ALADI, Asociación Latinoamericana de Integración

ARGM, Alto Representante General del Mercosur

CEPAL, Comisión Económica Para América Latina y el Caribe de Naciones Unidas

CMC, Consejo Mercado Común del Mercosur

$\mathrm{CPC}$, Comisión Parlamentaria Conjunta

CRPM, Comisión de Representantes Permanentes del Mercosur

FEM, Foro Especializado Migratorio

FOCEM, Fondo de Convergencia Estructural del Mercosur

POP, Protocolo de Ouro Preto

TPRM, Tribunal Permanente de Revisión del Mercosur 